\title{
(Bad) Luck or (Lack of) Effort?: Comparing Social Sharing Norms between US and Europe*
}

\author{
Pedro Rey-Biel ${ }^{\mathrm{a}}$, Roman Sheremeta ${ }^{\mathrm{b}}$ and Neslihan Uler $^{\mathrm{c}}$ \\ ${ }^{a}$ Universitat Autònoma de Barcelona, Departmento de Economía e Historia Económica, \\ Dpcho B3-166, Edifici B, Campus Bellaterra 08193 Bellaterra, Barcelona, Spain. \\ ${ }^{\mathrm{b}}$ Argyros School of Business and Economics, Chapman University, \\ One University Drive, Orange, CA 92866, U.S.A. \\ ${ }^{\mathrm{c}}$ Research Center for Group Dynamics, Institute for Social Research, \\ University of Michigan, 426 Thompson, Ann Arbor, MI.
}

September 28, 2011

\begin{abstract}
We compare the determinants of individual giving between two countries, Spain and the US, which differ in their redistribution policies and their beliefs over the causes of poverty. By varying the information about the determinants of income, we find that, although overall giving is similar in both countries when subjects know the actual role of luck and effort, Spanish subjects give more when they are uninformed compared to American subjects. Using elicited beliefs, we find that this is due to Spanish subjects associating poverty with bad luck and Americans believing that low performers did not work hard enough.
\end{abstract}

JEL Classifications: C72, C91, D63, D81, H50

Keywords: individual giving, cross-cultural, beliefs, laboratory experiment

Corresponding author: Neslihan Uler, Email: neslihan@umich.edu, Phone: (734) 763-6633.

* We thank Miguel A. Ballester, Yan Chen, Jim Hines, Chris House, Silvana Krasteva, Michal Krawczyk, Erin Krupka, Yusufcan Masatlioglu, Louis Putterman, Joel Slemrod, Erik Sorensen, Jeff Smith and seminar participants at School of Information at University of Michigan, the Department of Economics at University of Michigan, University of Texas Dallas and participants at the International Economic Science Association Conference in Chicago and Political Economy of Conflict Conference in Berlin. Pedro Rey-Biel acknowledges financial support from Ministerio de Ciencia y Tecnología (ECO2009-07616), Barcelona GSE Research Network and of the Government of Catalonia. Neslihan Uler thanks Russell Sage Foundation for financial support. Roman Sheremeta thanks Economic Science Institute and Chapman University for financial support. Any remaining errors are ours. 


\section{Introduction}

Despite abundant interdisciplinary research on the subject, the reasons why individuals donate a portion of their income, support charities or are in favor of redistributive policies remain largely unknown. An important piece of the explanation may rely on beliefs regarding how income inequality is generated. In particular, those who believe economic outcomes mainly depend on individual effort, may oppose redistribution towards poor individuals, since they may believe their poverty is due to slacking. On the other hand, those who believe other factors, not under an individual's control, are crucial in determining economic outcomes, may be more in favor of redistribution to the poor, since they may attribute poverty not only to individual responsibility. In fact, Alesina, Glaeser and Sacerdote (2001), Alesina and Glaeser (2004), Benabou and Tirole (2006) and Fernández (2010) argue that differences in redistributive norms between the US and Europe are related to differences in perceptions about how income inequality arises. Alesina and Angeletos (2005) provide a theoretical model suggesting that Europe has higher redistribution policies than US because Europeans believe that luck and connections have strong effects on wealth, whereas Americans believe that personal effort determines wealth.

We study giving and perceptions about the determinants of others' wealth in a controlled environment using a laboratory experiment conducted with subjects from the US and from a representative European country, namely Spain. According to The World Values Survey (1995), $68 \%$ of respondents in Spain said "poverty is due to unfair society" while only $16 \%$ said "poverty is due to laziness and lack of willpower." These results place Spain on the other side of 
the spectrum with respect to the US, where these percentages are $30 \%$ and $48 \%$, respectively. ${ }^{1}$ Using an experiment in which individual income is partially determined by real effort and partially by luck, we investigate whether there exist cross-cultural differences in giving between subjects in these two countries and whether these differences depend on how informed individuals are about how others' income has been determined. In particular, using a treatment in which these factors are unknown, we study whether individual beliefs about the effort levels and the degree of luck of others differ and, in such case, whether these differences in beliefs explain differences in voluntary giving. Finally, using individual information on personal characteristics and values, obtained through a survey, we investigate whether individual giving and beliefs are related to values, perceptions about inequality and political orientation.

There have been previous research investigating the relationship between the level of income and giving. This relationship is important since it could be argued that differences in sharing norms between the US and Spain may be due to inherent differences in wealth. The evidence is mixed. While Eckel, Grossman and Milano (2007) find a positive relationship, Auten, Clotfelter and Schmalbek (2000) find a U-shaped relationship between income and individual giving. Some studies do not find any significant relationship at all (Andreoni and Vesterlund, 2001; Buckley and Croson, 2006). A recent study by Erkal, Gangadharan and Nikiforakis (2010) shows that subjects who rank first in a tournament give significantly less than subjects who rank second in the tournament. ${ }^{2}$

\footnotetext{
${ }^{1}$ The US and Spain have been the focus of other cross-cultural experimental studies. Alm, Sanchez and De Juan (1995) find higher tax compliance in US compared to Spain. However, Brandts, Saijo and Schram (2004) do not find significant differences in contributions to a public good game across the US, Spain, Japan and the Netherlands.

${ }^{2}$ Most of these studies involve a small number of subjects interacting with each other. However, the demand for redistribution in the context of taxation with large groups has also been investigated (Durante and Putterman, 2009; Ackert et al., 2007; Krawczyk, 2010; Esarey, Salmon and Barrilleaux, 2011; Beckman et al., 2004).
} 
Most related to our purposes is the relationship between how income is determined and giving. Hoffman et al. (1994) show that entitlements play an important role in giving decisions. For example, they use an experiment to show that when agents earn the right to be the dictator, they give less in the dictator game. Similarly, Cherry, Frykblom and Shogren (2002) and Oxoby and Spraggon (2008) show that dictators give (take) less when income is earned by the dictators (recipients) compared to when income is determined by the experimenter.

Our experimental design goes one step further by allowing income to be determined by two factors, individual (real) effort and luck, and by varying the information subjects have about such determinants. In most of the previous experimental literature income is randomly determined by the experimenter or it depends solely on individual effort, while in our experiment both aspects play a role. Many economic experiments study how individuals give when all determinants of income are known, see the recent surveys by Andreoni (2006) and Vesterlund (2006). Konow (2000), Cappelen et al. (2007) and Konow et al. (2009) study different fairness principles when all determinants of income, such as effort and luck, are known and find that relative preferences for equity and equality differ across individuals. Most related to our work, Fong (2001 and 2007) investigate the impact of beliefs on redistributive preferences. In particular, Fong (2007) studies the determinants of generosity by controlling how much information subjects have regarding real-life welfare recipients. To our knowledge, our paper offers the first cross cultural comparison between two countries with opposing beliefs about the determinants of income, using an experiment in which beliefs about such determinants are elicited in an incentive compatible manner and in which initial income is determined by a combination of a real effort task and a random shock. ${ }^{3}$

\footnotetext{
${ }^{3}$ Ubeda (2010) uses a similar experimental design, although without cross cultural comparisons and only with the equivalent to our no information treatment, to compare the consistency of different fairness rules.
} 
In the first stage of our experiment subjects earned their income through a real effort task, consisting in counting the number of certain specific letters in a fixed number of sequences. Subjects' initial income was determined both by the number of individual correct counts (piecerate scheme) and a random number (luck), which took values zero on average. ${ }^{4}$ The second stage of the experiment was a two-person distribution decision. A two-person dictator game was used to elicit preferences for giving (degree of altruism), which govern the tradeoffs that one makes between his or her own payoffs and the payoffs of others (e.g., Forsythe et al., 1994; Hoffman et al., 1994; Andreoni and Miller, 2002; Charness and Rabin, 2002; Fisman et al., 2007). Our experimental design allows us to answer several interesting questions that the previous papers fall short off. In particular, we are able to investigate the interaction of effort and luck on voluntary giving. For example, among others, we can examine whether unlucky individuals get compensation independently of their effort level or whether individual luck determines giving towards slackers. In our experiment, we vary the information presented to subjects, i.e. whether or not subjects could observe how others' income was determined. The uninformed treatment allows us to use incentives that elicit individual beliefs about how the income of the other participant is generated. Finally, at the end of the experiment we conducted a survey on personal characteristics and values, and perceptions regarding how inequality is generated outside the lab.

Our results indicate that while the overall amount of giving is similar between the two countries, there exist important cross-cultural differences when subjects are uninformed about the determinants of others' income. In the uninformed treatment, Spanish subjects transfer a larger amount of their income and more frequently than American subjects. Spanish subjects

\footnotetext{
${ }^{4}$ We used a piece rate scheme and a task not depending on cultural differences and/or skill in order to control for preferences for competition across different cultures and to minimize the role of skill/knowledge on earnings. Some experiments employ tournaments to determine earnings, or rely on skill or knowledge related tasks (Erkal, Gangadharan and Nikiforakis, 2010; Cherry, Frykblom and Shogren, 2002).
} 
give more when they get luckier while Americans do not condition their giving to their own luck and transfer a flat amount. Regarding beliefs, low performing subjects believe others have more luck than themselves, partially justifying their poor performance and their scarce altruism. Additionally, own luck does not bias beliefs regarding others' luck. Spanish subjects on average have more accurate and unbiased beliefs about the performance of others. On the other hand, Americans believe that other subjects did not work hard enough when they observe low performance, and that other subjects are hardworking when they observe high performance. Differences in giving behavior are thus consistent with differing beliefs across the two countries. Regarding the treatment where subjects have information about the determinants of others' income, we find that in both countries poor subjects receive larger transfers independent of their effort level, implying that, as expected, low earnings are the driving force behind altruistic giving. Finally, we show that, proportion of income that comes from own work, importance of leisure and personal belief on whether effort or luck is more important in determining earnings affect transfer decisions.

The remainder of the paper is organized as follows. Section 2 describes the experimental design and procedures. Section 3 provides our findings. Section 4 concludes. The Appendices contain the experimental instructions and the values survey.

\section{Experimental Design and Procedures}

Ten experimental sessions were conducted at Universitat Pompeu Fabra in Barcelona, Spain and University of Michigan, USA. ${ }^{5}$ A total of 186 subjects participated in the study. The computerized experimental sessions used z-Tree experimental software (Fischbacher, 2007). All

\footnotetext{
${ }^{5}$ Both universities share similar aspects: they are both one of the largest universities in their countries, and they are both public schools.
} 
sessions were conducted by the same bilingual experimenter, who specifically rehearsed to repeat cultural-free instructions in both countries. Subjects were given the instructions, shown in Appendix A, at the beginning of the session and the experimenter read the instructions aloud. At the end of the experiment, subjects were paid in private and in cash.

Experiments were double-blind. Nobody, not even the experimenter, knew how much each subject earned from the experiment. Subjects earned approximately $\$ 20(15 €)$ on average, and sessions (including instruction time) lasted approximately 70 minutes. Instructions were written in English and then translated into Spanish. Two independent assistants translated the instructions back to English to check for any inconsistencies.

The experimental design consists of two treatments as summarized in Table 1: informed (INFO) and uninformed (UNINFO). In the first stage of both treatments (the earning stage) subjects had 30 minutes to count the sum of "a" and "d" characters contained in 50-character sequences. ${ }^{6}$ Characters included letters, punctuation marks, numbers, and symbols. Subjects were told that their earnings (in Tokens) were determined from the sum of the number of correct counts (effort) and a random number (luck) drawn from a discrete uniform distribution which could take values $-50,-25,0,+25$, or $+50 .{ }^{7}$ Subjects were also told that they could stop counting characters or take a break whenever they want. At the end of the experiments, subjects' earnings were converted to US Dollars or Euros at a conversion rate of 1 Token $=\$ 0.15$ and 1 Token $=$ $0.1 €$, which is very close to the currency exchange rate at the time. In the following, all results will be reported in tokens.

\footnotetext{
${ }^{6}$ There were 300 sequences, which is more than anyone could finish within the allocated time. The task is inspired by Gneezy and List (2006), who use data entry in a university library. Our task is similar to Abeler et al. (2011), where subjects had to count the number of zeros in tables that consist of 150 randomly ordered zeros and ones. Such tasks are mainly effort-related and not skill-related, i.e., success in such a task is mainly attributed to hard work more than to individual skill.

${ }^{7}$ In case the random number was negative and the number of correct counts was less than the absolute value of the random number, the computer set earnings for the first part to zero.
} 
In the second stage of the experiment, the redistribution stage, subjects had an opportunity to redistribute their earnings, determined by their correct number of counts plus their random number. Subjects were matched in pairs and played a 2-player dictator game. Each subject received the information about their own number of correct counts in the earning stage and their own random number drawn by the computer. In the INFO treatment, subjects also received the same information regarding their matched participant, while in the UNINFO treatment this information was omitted, such that subjects were only told about the earnings of their matched participant (i.e., the sum of the random number and number of correct counts). For each pair, the computer randomly determined which of the two decisions would count to determine payments. ${ }^{8}$

Finally, treatment UNINFO contained a third stage, which was not present in the INFO treatment. In this third stage, we used incentivized elicitation of subjects' beliefs about the other subject's random number, rewarding an exact correct guess with 10 extra tokens.

At the end of the experiment, and while subjects waited to be paid, we used a questionnaire to elicit self-reported measures about perceptions, personal values and personal characteristics. The questionnaire is available in Appendix B.

\section{Results}

\subsection{Descriptive Statistics}

We start with descriptive statistics. Table 2 reports the average number of correct counts in the first stage of the experiment, the average transfer, the percentage of positive transfers and

\footnotetext{
${ }^{8}$ Iriberri and Rey-Biel (2011) show that in modified dictator games using role uncertainty subjects give more than in treatments in which the role of dictator is assigned ex-ante. Brandts and Charness (2011) survey the methodological literature on the strategic method and similar other cost-saving procedures and argue that the evidence against using them is, at most, mixed. In any case, the cross country comparison should not be affected.
} 
the average transfer among those who transfer a positive amount. ${ }^{9}$ A Mann-Whitney nonparametric test cannot reject the null hypothesis that the average number of correct counts is the same in any of the two treatments and two countries, confirming the task chosen is not culturally biased. ${ }^{10}$ This is not surprising since ex-post all treatments in the first stage are identical.

Looking at individual giving, we again do not observe statistical differences in the average transfer (2.5 tokens) or in the proportion of positive transfers between the two treatments (32\% and $35 \%)$, when taking data from the two countries together. ${ }^{11}$ However, a pattern emerges when separating data by country and treatment: while in Spain average transfers and the proportion of donors is higher in the UNINFO treatment than in the INFO treatment, the opposite occurs in the US. Spanish subjects increase their average giving from 2.2 to 3.6 (one-tail test, pvalue $=0.06$ ), while Americans (insignificantly) decrease their average giving from 2.8 to 1.8 (one-tail test, $\mathrm{p}$-value $=0.20$ ) between INFO and UNINFO treatments. $^{12}$ There are no crosscultural differences in average transfers in the INFO treatment ( $\mathrm{p}$-value $=0.69)$. However, there are differences across countries for the UNINFO treatment. The average transfer in Spain is significantly higher than the mean transfer in the USA (one-tail test, p-value $=0.03$ ). Regarding the percentage of individuals who make a positive transfer in the INFO treatment, there is again no difference in the proportion of positive transfers between American and Spanish subjects (proportion test, $p$-value $=0.84$ ). However, in the UNINFO treatment, $27 \%$ of subjects in the US

\footnotetext{
${ }^{9}$ Results reported in the paper do not include the two outliers who gave all their earnings, since we suspect that these two subjects did not understand the instructions. Main findings of the paper are not sensitive to this elimination.

${ }^{10}$ Unless otherwise noted, all reported tests are two-tailed Mann-Whitney tests.

${ }^{11}$ The $\mathrm{p}$-value for the difference in average transfers is 0.74 , and the $\mathrm{p}$-value for the difference in proportions is 0.38 (one-tail proportion test).

${ }^{12}$ We observe an increase in giving by Spanish when subjects are uninformed; even though inequality in earnings decreased in the UNINFO treatment compared with the INFO treatment (standard deviation of earnings in the informed treatment is 45 , while the standard deviation of earnings in the uninformed treatment is 41 ). On the contrary, Americans give less in the UNINFO treatment, even though the standard deviation of earnings is higher in that treatment (45 compared to 40 ).
} 
make a positive transfer, which is significantly lower than the corresponding $44 \%$ in Spain (onetail proportion test, $\mathrm{p}$-value $=0.05){ }^{13}$

\subsection{Determinants of Giving}

Although nonparametric tests give us insights about giving decisions across treatments and cultures, they are not entirely informative since they do not control for important variables, such as each individuals' effort or how the random shock affected each subject. We thus turn to OLS regression analysis ${ }^{14}$ to control for these relevant factors in giving decisions. Table 3 regresses the transfer using as regressors the individual number of correct counts (own-effort and other-effort), each individuals' random shock (own-luck and other-luck) and, in treatment UNINFO, the performance of the others (other-performance), since subjects cannot distinguish between others' effort and luck.

We start with the INFO treatment. Regression (1) shows the result for both countries altogether, while regression (2) shows results for Spain and regression (3) for the US. In general, and as expected, transfers are higher for individuals with higher earnings, i.e., those who work harder and those who receive a positive random shock. Thus, although not always significant, the coefficients of own-effort and own-luck are positive. Similarly, those with lower earnings, i.e, those who either do not work hard and/or receive a negative shock, receive higher transfers. Thus the coefficients from other-effort and other-luck are negative, although only significantly so for

\footnotetext{
13 In addition, comparing the INFO and UNINFO treatments for the same country, we see that the proportion of individuals who make positive transfers increases in Spain and it decreases in the US. These differences are not statistically significant (one-tail proportion tests, $\mathrm{p}$-value $=0.11$ for Spain and $\mathrm{p}=0.27$ for US).

${ }^{14}$ For robustness checks, we also performed Tobit regression analysis since transfers in the INFO and UNINFO treatments are bounded below by zero. The qualitative results are very similar and are available from authors upon a request.
} 
other-effort. Table 3 also contains tests comparing the size of the regressors. We see that othereffort affects giving more than other-luck $(\mathrm{p}$-value $=0.00) .{ }^{15}$

Regression (2) indicates that, when uniformed, Spanish subjects condition their transfers on their own luck and the effort of the others. Particularly, the amount of transfer increases in the extent of own-luck and decreases with other-effort. Intuitively, subjects who benefit from a positive shock have higher income and tend to share their good luck with others; specifically those who have lower income, possibly as a consequence of their lower effort. Regression (3) shows that American subjects only condition their transfers on other-effort. However, when we run separate regressions to check whether Spanish and American condition their giving differently, we observe no differences among countries (p-values are all larger than 0.39$).{ }^{16}$

Finally, for the INFO treatment, we also looked whether there is an interaction between other subjects' effort and luck on individual transfer decisions. Using identical regressions as (1) to (3) in Table 3 and an additional interaction term between other-effort and other-luck we found no significant interaction effect. ${ }^{17}$ Therefore, we can conclude that, when informed, subjects make transfers to those with low effort independent of their random number showing that the driving force behind giving is low earnings. In fact when we regress transfers on ownperformance and other-performance, we see that transfers significantly increase with ownperformance $(\mathrm{p}$-value $=0.02)$ and significantly decrease with other-performance $(0.01)$.

Another way to see that subjects give more to the individuals with low effort (and hence do not punish lazy individuals) is to directly look at the summary statistics. Table 4 shows that

\footnotetext{
15 As we will argue later in the paper, participants give significantly more to subjects with low performance. Subjects with low effort levels are not penalized.

${ }^{16}$ When regressing transfers on a country specific dummy, usa, and interaction of this dummy with all the other relevant variables such as in Table 3, we find that only own-luck and other-effort significantly affects giving. The country specific dummy and the interaction terms do not significantly affect giving.

${ }^{17}$ The estimation results are available for the authors upon request.
} 
the transfers in the INFO treatment decrease with other subject's performance. More surprisingly, controlling for negative luck, transfers are higher for low effort subjects (one-tail Mann-Whitney test, p-value $=0.04)$ : an unlucky subject receives 1.36 on average if he puts high effort, versus he receives 5.52 on average if he puts low effort (one-tail Mann-Whitney test, pvalue $=0.01)$

Regressions (4) to (6) in Table 3 include the results for the UNINFO treatment. In the UNINFO treatment subjects were not informed about others' number of correct counts or the result of their random shock, but the result of both things combined. Thus, we use as regressor other subjects' earnings (other-performance), which is the result of both. When taking data from both countries together, regression (4), subjects do not condition their giving on any variable. As in the INFO treatment, the amount transferred increases in the extent of own-luck for Spanish subjects, but not for American subjects. Moreover, the coefficients of own-luck and otherperformance have opposite signs and are significantly different among Spanish and American subjects. Spanish subjects relative to American subjects increase their giving when they receive a positive shock $(\mathrm{p}$-value $=0.04)$ and they also increase their giving when others have better performance $(\mathrm{p}$-value $=0.03)$. It is interesting to observe that the coefficient of otherperformance is positive for Spanish subjects. In contrary to treatment INFO, the driving force behind giving is not low earnings. For all subjects, when we regress transfers on ownperformance and other-performance, we find that giving increases with these two factors but the relationship is not significant at the $10 \%$ level (p-values are 0.11 and 0.13 respectively). ${ }^{18}$

Previous literature on two-person dictator games (Hoffman et al., 1994; Cherry, Frykblom and Shogren, 2002; Cappelen et al., 2007; Oxoby and Spraggon, 2008) suggests that

\footnotetext{
18 The positive relationship between both giving and own-performance, and giving and other-performance are significant for Spanish subjects (p-values are 0.06 and 0.05 , respectively).
} 
individuals are more generous when their wealth depends solely on a random shock, which would explain why Spanish subjects who receive a positive shock increase their giving. However, while this seems to be true for Spanish subjects for both INFO and UNINFO treatments, we do not see any evidence on this for American subjects when earnings are determined partly by effort and partly by luck, especially when American subjects are uninformed regarding how income of the other participant is generated.

We have seen that the only difference across cultures is for treatment UNINFO, where subjects are uninformed regarding the effort and luck of the other subject. We investigate whether this difference is consistent with how individuals form their beliefs.

\subsection{Beliefs about Others' Luck}

In treatment UNINFO (after subjects make their giving decisions), we have elicited the beliefs of subjects regarding the random number of their paired participants. Comparing beliefs with the actual realization of the random number, we find that on average $50 \%$ of subjects guess the random number correctly (see Figure 1). Moreover, both Spanish and American subjects have similar accuracy and belief structures. The distributions are not significantly different from each other ( $\mathrm{p}$-value $=0.60$ ), and the average amount of deviation (belief-number) is not significantly different than zero for both countries (sign-rank tests, p-values are greater than $0.69)$.

It is interesting to look at the beliefs when other subject's performance is lower than average (see Figure 2). Americans predict significantly higher random numbers compared to the actual values (signed-rank test, p-value $<0.01$ ). This suggests that American subjects believe that others have low income because they did not work hard enough. This is consistent with the lower 
proportion of Americans contributing positive amounts in treatment UNINFO. We cannot reject the null hypothesis that on average Spanish subjects guess correct numbers (signed-rank test, pvalue $=0.41) .{ }^{19}$ Moreover, when comparing Spanish to American subjects, the distributions are also marginally different (one-tail test, $\mathrm{p}$-value $=0.08) .^{20}$

Similarly, we look at the cases where other subject's performance is higher than average (see Figure 3). In this case we see that histograms are skewed to the left. Americans guess lower random numbers than actual numbers (signed-rank test, p-value $<0.01$ ). On the other hand, Spanish subjects guess correct numbers on average (signed-rank test, p-value $=0.27$ ). The difference in beliefs between American and Spanish subjects is marginally significant (one-tail test, $\mathrm{p}$-value $=0.10$ )

Next, we investigate whether the previous result is robust by controlling for effort, luck, individual perceptions and characteristics. The estimation results are in Table 5. Not surprisingly, we find strong positive correlation between beliefs and other-performance. This indicates that when subjects observe higher performance by others, they tend to believe that such high performance was significantly influenced by luck. Interestingly, beliefs are also significantly correlated with own-effort. Subjects with lower effort levels guess higher numbers. In other words, when they see high performance, they tend to believe that luck plays an important role.

In specification (1), we can see that Americans guess higher numbers when they see low performance but guess lower numbers as other-performance increases (the coefficient of usa is

\footnotetext{
${ }^{19}$ This doesn't mean that Spanish subjects have accurate beliefs on average in terms of Bayesian updating. Since every subject may have a different prior on effort distribution, it is not easy to know how Bayesian updating would result for a given subject. However, on average, we expect Bayesian subjects to guess lower random numbers compared to true numbers when other's performance is low.

${ }^{20}$ When we regress transfers in the UNINFO treatment on beliefs, effort, luck, and other-performance (clustered at country level), we observe a weak negative correlation between transfers and beliefs ( $\mathrm{p}$-value $=0.14)$. Although one would expect to have a more significant effect of beliefs on actions, we have to keep in mind that we have only one observation per individual so we don't have controls for individual altruism. Since some people are unconditional givers and some are purely selfish, it is not that surprising to have a low correlation. We conjecture that one would observe much higher levels of correlation with more observations per individuals.
} 
positive but the coefficient of the interaction term is negative). This is especially true for subjects with low performance, where usa and the interaction term are both significant at the $15 \%$ (see specification 3). Moreover, when we add individual controls (specification 6), these coefficients are now highly significant for low performers. ${ }^{21}$

\subsection{Personal Characteristics}

Before the experiment concluded, subjects answered questions regarding their personal characteristics, beliefs and perceptions (see Appendix B for the questionnaire). ${ }^{22} \mathrm{We}$ asked subjects to report how hard they considered they had worked on the real effort task, using a scale from 1 to 10. Subjects also reported their gender, age, birthplace, income, and what proportion of that income comes from their own work, as well as their personal values regarding issues such as family, religion, leisure, work; on political orientation (politics), or government responsibilities. Finally, subjects were asked about their personal belief whether hardworking brings success or whether success is a matter of luck and connections.

Table 6 provides summary statistics for each of these variables. Although gender and age composition of our subject pools are similar, there are several important differences across cultures which may affect the transfer decisions. We find that Americans report that they are more religious and they put more importance on leisure time ${ }^{23}$; they have higher family values and income (although the proportion of income that comes from work is not significantly different across cultures). Spanish subjects believe more heavily that hardworking doesn't bring

\footnotetext{
${ }^{21}$ An interpretation of this finding is that in the USA low performing subjects do not believe high performance is due to good luck compared with the subjects in Spain. This is consistent with the fact that in the USA, median voter does not favor high redistribution.

${ }^{22}$ Questionnaire data from session 8 of our experiment was lost due to a problem with the server. Thus, this section only includes data from the remaining sessions.

${ }^{23}$ Reporting a higher value for leisure does not necessarily mean Americans enjoy longer leisure time. In contrary, they may be valuing leisure more if they have (or perceive to have) a lower level of leisure time.
} 
success and that the government should take more responsibility to ensure everyone is provided for. Spanish subjects agreed more with the statement "less importance should be placed on work in our lives." We also see that Americans report higher numbers than Spanish when they are asked how hard they worked on the real effort task, even though on average both cultures have similar correct counts.

We now check whether personal characteristics and values significantly affect how people decide on their transfers. Table 7 presents the estimation results of several OLS regressions, where the dependent variable is how much is transferred and the independent variables are personal characteristics of subjects as well as own-performance and the performance of the matched subject. ${ }^{24}$ In treatment INFO, we see that none of these personal characteristics affect giving at the 5\% level. For treatment UNINFO, the proportion of income that comes from own work positively affects transfers for Spanish subjects (but not for American subjects). We also see a correlation between giving and leisure. Leisure is a multinomial variable from 1 to 6 that shows whether individuals find leisure important in their lives, where 1 corresponds to "extremely important." In general, individuals who find leisure important in their lives give significantly less. The same result holds for Spanish subjects at the $10 \%$ level but not for Americans. Finally, subjects who agree more with the statement "Hard work doesn't bring success - it is more a matter of luck and connections" give more at the $10 \%$ level. However, we do not see any significant correlation when we look at the cultures separately.

We also investigated the determinants of beliefs regarding the random number and found that in addition to own-effort and other-performance, income levels affect beliefs. ${ }^{25}$ Specifically,

\footnotetext{
${ }^{24}$ Since, in our experiment, subjects only make one transfer decision, we do not have enough observations, and therefore these results should be interpreted with caution.

${ }^{25}$ The estimation results are available from the authors upon request.
} 
we found that lower income individuals guess higher numbers. This is intuitive as lower income individuals may be more likely to associate success with luck.

Since in our study, we also control for the origin of birthplace, we can check whether subjects with different birth origins behave differently. Even though most of the subjects in Spain were born in Europe, approximately one-fourth of American subjects were not born in the $\mathrm{US}^{26}$ We examine whether these aliens have the same giving norms as the American subjects that born in the US. We do not find differences in transfers between American subjects that born in the US and aliens ( $p$-value $=0.27$ for treatment INFO and $p$-value $=0.80$ for treatment UNINFO). Additionally, we do not find any significant differences across the proportion of positive transfers (proportion tests, $\mathrm{p}$-value $=0.11$ for treatment INFO and $\mathrm{p}$-value $=0.38$ for treatment UNINFO). Finally, we do not observe any differences in determinants of giving across these two groups of American subjects.

\section{Conclusion}

We study individual giving by subjects whose initial income is determined partially by real effort and partially by luck. In our experiment we vary the informational conditions by letting subject know (or not) how others' income has been determined, i.e., whether others' income is solely the result of hard work or whether good or bad luck has influenced others' performance. Our results indicate that transfers decrease with other participant's effort. Surprisingly, low effort is not punished: participants with low effort and low luck receive the largest transfers. However, when subjects are uninformed regarding how the income of the paired participant is generated, subjects give a flat rate and they do not condition their giving. In

\footnotetext{
${ }^{26}$ Only 5 subjects in Spanish subject pool were not born in Europe versus 23 subjects in American subject pool were not born in the US.
} 
the uninformed treatment we observe cross-cultural differences. Spanish subjects are more generous, and they give more frequently compared to American subjects. This difference may be due to different beliefs. While Spanish subjects have more accurate beliefs, Americans believe that others did not work hard enough when they see low performance. The latter finding provides a direct (incentivized) support for the 1995 World Values Survey which documents that $48 \%$ of Americans and only $16 \%$ of Spanish believe that "poverty is due to laziness and lack of willpower."

Our study also increases our understanding regarding different fairness ideals such as strict egalitarianism, libertarians and liberal egalitarians (Konow, 2000; Cappelen et al., 2007; Konow et al., 2009). While strict egalitarians consider equal sharing a fair distribution, libertarians oppose redistribution and liberal egalitarians believe individuals should not be held responsible for circumstances beyond their control. As in Cappelen et al. (2007, 2011), in a twoperson dictator game, we find evidence for liberal egalitarianism for European subjects, i.e., Spanish subjects condition their giving on own-luck, but not on own-effort. ${ }^{27}$ In contrast, we find that American subjects do not condition their giving neither on own-luck, nor on own-effort. American subjects, who give, seem to be unconditional givers.

Finally, our study helps to shed light on why previous studies do not always agree on what is the relationship between the level of income and giving, i.e. positive, negative or none (Andreoni and Vesterlund, 2001; Buckley and Croson, 2006; Eckel, Grossman and Milano, 2007; Erkal, Gangadharan and Nikiforakis, 2010). In particular, the results of our experiment suggest that the uncertainty regarding how income is generated and cultural differences affect the relationship between income and transfers.

\footnotetext{
${ }^{27}$ Cappelen et al. (2007) conducted their experiment in Norway, while Cappelen et al. (2011) conducted their webbased experiment in Norway, Germany, Uganda and Tanzania.
} 


\section{References}

Abeler, J., Falk, A., GÄotte, L., and Huffman, D. (2011) "Reference Points and Effort Provision." American Economic Review,101(2), 470-492.

Ackert, L. F., Martinez-Vazquez, J., Rider, M. (2007) "Social Preferences and Tax Policy Design: Some Experimental Evidence." Economic Inquiry, 45, 3, 487-501.

Alesina, Alberto F. and Edward L. Glaeser (2004) Fighting poverty in the U.S. and Europe: A world of difference. Oxford, U.K.: Oxford University Press.

Alesina, Alberto F. and G. M. Angeletos (2005) "Fairness and Redistribution." American Economic Review, 95(4): 960-980.

Alesina, Alberto F., Glaeser, Edward L. and Sacerdote, Bruce (2001) "Why Doesn't the US Have a European-Style Welfare System?" NBER Working Paper No. W8524. Available at SSRN: http://ssrn.com/abstract=286196

Alm, J. Sanchez, I. and De Juan, A. (1995) "Economic and Noneconomic Factors in Tax Compliance." Kyklos, 48, 3-18.

Alm, James and Benno Torgler (2006) "Culture Differences and Tax Morale in the United States and in Europe." Journal of Economic Psychology, 27, 224-246.

Andreoni, James \& Vesterlund, Lise (2001) "Which Is The Fair Sex? Gender Differences In Altruism." Quarterly Journal of Economics, 116(1), 293-312.

Andreoni, James (2006) "Philanthropy." Handbook of Giving, Reciprocity and Altruism, Amsterdam: North Holland, 1201-1269.

Andreoni, James and James Miller (2002) "Giving According to GARP: An Experimental Test of the Consistency of Preferences for Altruism." Econometrica, 70 (2): 737-753.

Auten Gerald E., Sieg, Holger and Charles T. Clotfelter (2002) "Charitable Giving, Income and Taxes: An Analysis of Panel Data." American Economic Review, 92(1): 371-382.

Auten, G. E., Clotfelter, C., \& Schmalbeck, R. L. (2000) Taxes and philanthropy among the wealthy. In J. Slemrod (Ed.), "Does atlas shrug? The economic consequences of taxing the rich" (pp. 392-424). New York and Cambridge, MA: Russell Sage and Harvard University Press.

Beckman, S., Formby J.P., Smith, W. J. (2004) "Efficiency, Equity and Democracy: Experimental Evidence on Koun's Leaky Bucket," in Cowell, F., Inequality, Welfare and Income Distribution: Experimental Approaches, JAI Press.

Benabou, Richard and Jean Tirole (2006) "Belief In A Just World And Redistributive Politics." Quarterly Journal of Economics, 121(2), 699-746.

Brandts, J., Charness, G., (2011) "The Strategy versus the Direct-Response Method: a First Survey of Experimental Comparisons." Experimental Economics, 14(3): 375-398.

Brandts, Jordi, Tatsuyoshi Saijo, \& Arthur Schram, (2004) "How Universal is Behavior? A Four Country Comparison of Spite and Cooperation in Voluntary Contribution Mechanisms." Public Choice, 119, 381-424.

Buckley, Edward \& Croson, Rachel, (2006) "Income and wealth heterogeneity in the voluntary provision of linear public goods." Journal of Public Economics, 90(4-5), 935-955.

Cappelen, A.W., A.D. Hole, E. Sorensen and B. Tungodden (2011) "The Pluralism of Fairness Ideals: An Experimental Approach." Journal of the European Economic Association, forthcoming.

Cappelen, A.W., K. Moene, E. Sorensen and B. Tungodden (2007). "Needs vs entitlements - an international fairness experiment." American Economics Review, 97, 3, 818-827. 
Charness, Gary, and Matthew Rabin (2002) "Understanding social preferences with simple tests." Quarterly Journal of Economics, 117: 817-69.

Cherry, T. L., P. Frykblom and J. F. Shogren (2002) "Hardnose the Dictator." American Economic Review 92(4): 1218-1221.

Durante, R., and L. Putterman (2009) "Preferences for Redistribution and Perception of Fairness: An Experimental Study." Working paper.

Eckel, Catherine C., Philip J. Grossman and Angela Milano (2007) "Is More Information Always Better? And Experimental Study of Charitable Giving and Hurricane Katrina." Southern Economic Journal, 74(2): 388-411.

Erkal, Nisvan, Gangadharan, Lata, and Nikos Nikiforakis (2010) "Relative Earnings and Giving in a Real-Effort Experiment." American Economic Review, forthcoming.

Esarey, Justin, Tim Salmon, and Charless Barrilleaux (2011) "Social Insurance and Income Redistribution in a Laboratory Experiment." Political Research Quarterly, XX(X) 1-14.

Fernández, Raquel (2010). “Does Culture Matter?”. IZA Discussion Paper N. 5122.

Fischbacher, Urs (2007) "z-Tree: Zurich toolbox for ready-made economic experiments." Experimental Economics, 10(2), 171-178.

Fisman, Raymond, Kariv, Shachar, and Daniel Markovits (2007) "Individual Preferences for Giving." American Economic Review, 97(5): 1858-1876.

Fong, Christina (2001) "Social Preferences, self-interest, and the demand for redistribution." Journal of Public Economics, 82: 225-246.

Fong, Christina (2007) "Evidence From an Experiment on Charity to Welfare Recipients: Reciprocity, Altruism and the Empathic Responsiveness Hypothesis." Economic Journal, 1008-1024.

Forsythe, R., Horowitz, J.L., Savin, N. E. and Sefton, M. (1994) "Fairness in Simple Bargaining Experiments." Games and Economic Behavior, 6, 347-369.

Gneezy, U and J. List (2006) "Putting Behavioral Economics to Work: Field Evidence on Gift Exchange." Econometrica, 74(5) 1365-1384.

Hoffman, E., McCabe, K., Shachat, K., and Vernon Smith (1994) "Preference, Property Rights and Anonymity in Bargaining Games." Games and Economic Behavior, 7: 346-380.

Iriberri, N., Rey-Biel, P. (2011) "The Role of Role Uncertainty in Modified Dictator Games." Experimental Economics, 2, 160-180.

Konow, J., Saijo T. and Kenju A. (2009) "Morals and Mores: Experimental Evidence on Equity and Equality." Working paper.

Konow, James (2000) "Accountability and Cognitive Dissonance in Allocation Decisions" American Economics Review, 90, 4, 1072-1091.

Krawczyk, M. (2010) "A Glimpse through the Veil of Ignorance: Equality of Opportunity and Support for Redistribution." Journal of Public Economics, 94(1-2), 131-141.

Oxoby, Robert J. \& Spraggon, John (2008) "Mine and yours: Property rights in dictator games." Journal of Economic Behavior \& Organization, 65(3-4), 703-713.

Ubeda, Paloma (2010) “The Consistency of Fairness Rules: An Experimental Study.” Discussion Papers in Economic Behaviour 10/10. University of Valencia.

Vesterlund, Lise (2006) "Why do People Give?" in Richard Steinberg and Walter W. Powell eds., The Nonprofit Sector, 2nd edition, Yale Press. 


\section{Tables and Figures}

Table 1: Summary of Treatments

\begin{tabular}{cccc}
\hline \multirow{2}{*}{ Treatment } & \multicolumn{3}{c}{ Information about the Opponent's } \\
\cline { 2 - 4 } & Effort & Luck & Earnings \\
\hline INFO & Yes & Yes & Yes \\
UNINFO & No & No & Yes \\
\hline
\end{tabular}

Table 2: Descriptive Statistics (Averages by Treatment)

\begin{tabular}{lcccccc}
\hline \hline Treatment & $\begin{array}{c}\text { Number of } \\
\text { Observations }\end{array}$ & $\begin{array}{c}\text { Average } \\
\text { Correct Counts }\end{array}$ & $\begin{array}{c}\text { Average Transfer } \\
\text { (Amount Sent) }\end{array}$ & $\begin{array}{c}\text { Percentage of } \\
\text { positive transfers }\end{array}$ & $\begin{array}{c}\text { Average Positive } \\
\text { Transfer } \\
\text { (Amount sent) }\end{array}$ & Population \\
\hline \hline INFO & 99 & $79.5(19.3)$ & $2.5(5.6)$ & $32 \%$ & $7.8(7.6)$ & ALL \\
UNINFO & 87 & $80.0(15.2)$ & $2.5(4.9)$ & $35 \%$ & $7.3(6.0)$ & ALL \\
\hline INFO & 54 & $81.6(16.7)$ & $2.2(5.7)$ & $31 \%$ & $7.1(8.4)$ & Spain \\
UNINFO & 36 & $77.8(14.3)$ & $3.6(5.5)$ & $44 \%$ & $8.1(5.7)$ & Spain \\
\hline INFO & 45 & $77.4(21.9)$ & $2.8(5.6)$ & $33 \%$ & $8.5(6.9)$ & US \\
UNINFO & 51 & $81.5(15.7)$ & $1.8(4.3)$ & $27 \%$ & $6.4(6.4)$ & US \\
\hline
\end{tabular}

Note: Standard deviation in parentheses.

Table 3: Transfers Conditional on Effort and/or Luck (OLS)

\begin{tabular}{|c|c|c|c|c|c|c|}
\hline Treatment & \multicolumn{3}{|c|}{ INFO } & \multicolumn{3}{|c|}{ UNINFO } \\
\hline Country & All & Spain & US & All & Spain & US \\
\hline $\begin{array}{l}\text { Dependent variable, } \\
\text { transfer }\end{array}$ & (1) & (2) & (3) & (4) & (5) & (6) \\
\hline own-effort & $\begin{array}{c}0.03 \\
(0.03)\end{array}$ & $\begin{array}{c}0.02 \\
(0.04)\end{array}$ & $\begin{array}{c}0.03 \\
(0.04)\end{array}$ & $\begin{array}{l}0.02 \\
(0.04)\end{array}$ & $\begin{array}{l}-0.00 \\
(0.06)\end{array}$ & $\begin{array}{c}0.04 \\
(0.04)\end{array}$ \\
\hline own-luck & $\begin{array}{l}0.02 * \\
(0.01)\end{array}$ & $\begin{array}{l}0.04 * * \\
(0.02)\end{array}$ & $\begin{array}{c}0.02 \\
(0.02)\end{array}$ & $\begin{array}{c}0.02 \\
(0.01)\end{array}$ & $\begin{array}{l}0.05^{* *} \\
(0.02)\end{array}$ & $\begin{array}{l}-0.01 \\
(0.02)\end{array}$ \\
\hline other-effort & $\begin{array}{c}-0.11 * * * \\
(0.03)\end{array}$ & $\begin{array}{c}-0.12 * * * \\
(0.04)\end{array}$ & $\begin{array}{c}-0.09 * * \\
(0.04)\end{array}$ & & & \\
\hline other-luck & $\begin{array}{c}-0.02 \\
(0.01)\end{array}$ & $\begin{array}{l}-0.03 \\
(0.02)\end{array}$ & $\begin{array}{l}-0.01 \\
(0.02)\end{array}$ & & & \\
\hline other-performance & & & & $\begin{array}{l}0.02 \\
(0.01)\end{array}$ & $\begin{array}{l}0.04^{*} \\
(0.02)\end{array}$ & $\begin{array}{l}-0.01 \\
(0.02)\end{array}$ \\
\hline constant & $\begin{array}{l}8.90 * * \\
(3.46)\end{array}$ & $\begin{array}{c}10.84 * * \\
(5.24)\end{array}$ & $\begin{array}{c}7.38 \\
(5.51) \\
\end{array}$ & $\begin{array}{l}-0.94 \\
(3.19)\end{array}$ & $\begin{array}{c}-0.54 \\
(5.54)\end{array}$ & $\begin{array}{l}-0.80 \\
(3.65)\end{array}$ \\
\hline Observations & 99 & 54 & 45 & 87 & 36 & 51 \\
\hline Hypothesis & p-value & $\mathrm{p}$-value & p-value & p-value & p-value & p-value \\
\hline $\begin{array}{l}\text { own-effort }=\text { own-luck } \\
\text { other-effort }=\text { other-luck }\end{array}$ & $\begin{array}{c}0.89 \\
0.00 * * *\end{array}$ & $\begin{array}{c}0.68 \\
0.05^{* *}\end{array}$ & $\begin{array}{c}0.63 \\
0.05 * *\end{array}$ & 0.99 & 0.44 & 0.24 \\
\hline own-effort $=-$ other-effort & $0.06^{*}$ & 0.10 & 0.41 & & & \\
\hline own-luck $=$ - other-luck & 0.85 & 0.71 & 0.96 & & & \\
\hline
\end{tabular}

Note: * indicate statistical significance at the $10 \%$ level. $* *$ significant at 5\%; and *** at $1 \%$.

Standard errors are in parentheses. 
Table 4: Conditional Transfers in Treatment INFO

\begin{tabular}{lcccc}
\hline \hline & $\begin{array}{l}\text { other-effort } \geq 80 \\
\text { other-luck }>0\end{array}$ & $\begin{array}{l}\text { other-effort }<80 \\
\text { other-luck }>0\end{array}$ & $\begin{array}{c}\text { other-effort } \geq 80 \\
\text { other-luck } \leq 0\end{array}$ & $\begin{array}{c}\text { other-effort }<80 \\
\text { other-luck } \leq 0\end{array}$ \\
\hline Number of obs. & 17 & 24 & 33 & 25 \\
Mean transfer & 1.06 & 1.96 & 1.36 & 5.52 \\
Standard dev. & 2.68 & 3.03 & 3.82 & 9.14 \\
Median transfer & 0 & 0 & 0 & 0 \\
Min transfer & 0 & 0 & 0 & 0 \\
Max transfer & 10 & 10 & 16 & 32 \\
Average Payoff & 141.71 & 118.88 & 64.42 & 39.48 \\
\hline
\end{tabular}

Table 5: Beliefs Conditional on Effort and/or Luck

\begin{tabular}{llccccc}
\hline Own-Performance & All & $\begin{array}{c}\text { own- } \\
\text { perfor } \geq \\
80\end{array}$ & $\begin{array}{c}\text { own- } \\
\text { perfor } \\
80\end{array}$ & All & $\begin{array}{c}\text { own- } \\
\text { perfor } \geq \\
80\end{array}$ & $\begin{array}{c}\text { own- } \\
\text { perfor } \\
80\end{array}$ \\
\hline $\begin{array}{l}\text { Dependent variable, } \\
\text { belief }\end{array}$ & $(1)$ & $(2)$ & $(3)$ & $(4)$ & $(5)$ & $(6)$ \\
\hline usa & 6.65 & -2.88 & 24.31 & $15.36^{*}$ & 1.09 & $41.50^{* *}$ \\
& $(8.16)$ & $(10.76)$ & $(14.47)$ & $(8.74)$ & $(13.95)$ & $(16.22)$ \\
own-effort & $-0.52^{* * *}$ & $-0.61^{* * *}$ & $-0.36^{* *}$ & $-0.46^{* * *}$ & $-0.58^{* *}$ & $-0.37^{* *}$ \\
& $(0.11)$ & $(0.20)$ & $(0.16)$ & $(0.12)$ & $(0.27)$ & $(0.17)$ \\
own-luck & -0.02 & 0.08 & 0.05 & -0.01 & 0.14 & 0.00 \\
other-performance & $(0.04)$ & $(0.14)$ & $(0.16)$ & $(0.05)$ & $(0.16)$ & $(0.18)$ \\
& $0.72^{* * *}$ & $0.66^{* * *}$ & $0.87^{* * *}$ & $0.75^{* * *}$ & $0.69^{* * *}$ & $0.89^{* * *}$ \\
other-performance $\times$ usa & $(0.07)$ & $(0.08)$ & $(0.13)$ & $(0.07)$ & $(0.10)$ & $(0.14)$ \\
& -0.07 & 0.01 & -0.24 & -0.07 & 0.03 & $-0.32^{*}$ \\
\hline Observations & $(0.09)$ & $(0.12)$ & $(0.15)$ & $(0.09)$ & $(0.16)$ & $(0.16)$ \\
\hline
\end{tabular}

Note: * indicates statistical significance at $10 \%$ level, $* *$ at $5 \%$; and $* * *$ at $1 \%$.

Standard errors are in parentheses.

Table 6: Summary Statistics on Personal Characteristics/Views

\begin{tabular}{|c|c|c|c|c|c|c|c|}
\hline Country & \multicolumn{3}{|c|}{ Spain } & \multicolumn{3}{|c|}{ US } & "Mann-Whitney test \\
\hline & Mean & Min & Max & Mean & Min & $\operatorname{Max}$ & p-value \\
\hline hard & $5.89(1.83)$ & 1 & 9 & $8.09(2.02)$ & 1 & 10 & 0.00 *** \\
\hline female & $0.52(0.50)$ & 0 & 1 & $0.49(0.50)$ & 0 & 1 & 0.65 \\
\hline age & $21.71(2.93)$ & 18 & 32 & $21.41(3.43)$ & 18 & 43 & 0.28 \\
\hline income & $1.50(0.69)$ & 1 & 3 & $1.79(0.80)$ & 1 & 3 & $0.01 * *$ \\
\hline proportion & $2.63(1.34)$ & 1 & 4 & $2.52(1.34)$ & 1 & 4 & 0.57 \\
\hline family & $2.13(0.88)$ & 1 & 5 & $1.83(1.08)$ & 1 & 5 & $0.00 * * *$ \\
\hline religion & $5.30(1.20)$ & 1 & 6 & $3.93(1.69)$ & 1 & 6 & $0.00 * * *$ \\
\hline leisure & $2.66(0.77)$ & 1 & 5 & $2.40(1.00)$ & 1 & 6 & $0.03 * *$ \\
\hline politics & $2.94(1.24)$ & 1 & 7 & $3.20(1.23)$ & 1 & 6 & 0.16 \\
\hline work & $3.20(1.32)$ & 1 & 7 & $3.62(1.32)$ & 1 & 6 & $0.02 * *$ \\
\hline luck & $3.79(1.43)$ & 1 & 7 & $4.71(1.49)$ & 1 & 7 & $0.00 * * *$ \\
\hline government & $2.58(1.44)$ & 1 & 7 & $3.17(1.54)$ & 1 & 7 & $0.00 * * *$ \\
\hline birthplace & $7.78(1.53)$ & 1 & 10 & $2.37(2.41)$ & 1 & 10 & $0.00 * * *$ \\
\hline
\end{tabular}

Note: * indicates statistical significance at $10 \%$ level, $* *$ at $5 \%$; and $* * *$ at $1 \%$.

Standard deviation in parentheses. Spain has 90 and US has 86 data points. 
Table 7: Transfers Conditional on Personal Characteristics

\begin{tabular}{|c|c|c|c|c|c|c|}
\hline \multirow{2}{*}{$\begin{array}{l}\text { Treatment } \\
\text { Country }\end{array}$} & \multicolumn{3}{|c|}{ INFO } & \multicolumn{3}{|c|}{ "UNINFO } \\
\hline & ALL & Spain & US & ALL & Spain & US \\
\hline $\begin{array}{l}\text { Dependent variable, } \\
\text { transfer }\end{array}$ & (1) & (2) & (3) & (4) & (5) & (6) \\
\hline performance & $\begin{array}{l}0.02 * \\
(0.01)\end{array}$ & $\begin{array}{c}0.03 \\
(0.02)\end{array}$ & $\begin{array}{c}0.00 \\
(0.02)\end{array}$ & $\begin{array}{l}0.02 * \\
(0.01)\end{array}$ & $\begin{array}{c}0.02 \\
(0.03)\end{array}$ & $\begin{array}{c}0.01 \\
(0.02)\end{array}$ \\
\hline other-performance & $\begin{array}{c}-0.04 * * * \\
(0.01)\end{array}$ & $\begin{array}{c}-0.05 * * * \\
(0.02)\end{array}$ & $\begin{array}{l}-0.03 \\
(0.02)\end{array}$ & $\begin{array}{c}0.02 \\
(0.01)\end{array}$ & $\begin{array}{c}0.07 * * \\
(0.03)\end{array}$ & $\begin{array}{r}0.00 \\
(0.02)\end{array}$ \\
\hline hard & $\begin{array}{l}-0.14 \\
(0.29)\end{array}$ & $\begin{array}{l}-0.14 \\
(0.46)\end{array}$ & $\begin{array}{l}-0.05 \\
(0.45)\end{array}$ & $\begin{array}{c}0.17 \\
(0.25)\end{array}$ & $\begin{array}{c}0.61 \\
(0.63)\end{array}$ & $\begin{array}{c}0.25 \\
(0.35)\end{array}$ \\
\hline female & $\begin{array}{l}-2.03 \\
(1.27)\end{array}$ & $\begin{array}{l}-1.98 \\
(1.91)\end{array}$ & $\begin{array}{l}-2.89 \\
(1.96)\end{array}$ & $\begin{array}{c}0.10 \\
(1.17)\end{array}$ & $\begin{array}{l}1.73 \\
(2.15)\end{array}$ & $\begin{array}{l}-0.92 \\
(1.97)\end{array}$ \\
\hline age & $\begin{array}{c}0.03 \\
(0.25)\end{array}$ & $\begin{array}{l}-0.01 \\
(0.32)\end{array}$ & $\begin{array}{l}-0.24 \\
(0.57)\end{array}$ & $\begin{array}{l}-0.17 \\
(0.17)\end{array}$ & $\begin{array}{l}-0.41 \\
(0.47)\end{array}$ & $\begin{array}{l}-0.03 \\
(0.20)\end{array}$ \\
\hline income & $\begin{array}{l}-0.06 \\
(0.81)\end{array}$ & $\begin{array}{l}0.46 \\
(1.42)\end{array}$ & $\begin{array}{c}1.26 \\
(1.15)\end{array}$ & $\begin{array}{l}-0.43 \\
(0.78)\end{array}$ & $\begin{array}{l}-3.89 \\
(2.81)\end{array}$ & $\begin{array}{c}0.37 \\
(0.96)\end{array}$ \\
\hline proportion & $\begin{array}{l}-0.64 \\
(0.46)\end{array}$ & $\begin{array}{l}-1.53 * \\
(0.77)\end{array}$ & $\begin{array}{l}1.16^{*} \\
(0.66)\end{array}$ & $\begin{array}{l}0.73 * \\
(0.41)\end{array}$ & $\begin{array}{l}1.94 * * \\
(0.82)\end{array}$ & $\begin{array}{c}0.38 \\
(0.55)\end{array}$ \\
\hline family & $\begin{array}{l}-0.05 \\
(0.67)\end{array}$ & $\begin{array}{l}-0.75 \\
(1.00)\end{array}$ & $\begin{array}{c}0.98 \\
(1.10)\end{array}$ & $\begin{array}{l}-0.88 \\
(0.67)\end{array}$ & $\begin{array}{c}0.12 \\
(1.30)\end{array}$ & $\begin{array}{l}-0.91 \\
(0.85)\end{array}$ \\
\hline religion & $\begin{array}{c}0.39 \\
(0.45)\end{array}$ & $\begin{array}{l}0.11 \\
(0.85)\end{array}$ & $\begin{array}{c}0.29 \\
(0.55)\end{array}$ & $\begin{array}{l}-0.05 \\
(0.36)\end{array}$ & $\begin{array}{l}-0.71 \\
(1.09)\end{array}$ & $\begin{array}{l}-0.15 \\
(0.49)\end{array}$ \\
\hline leisure & $\begin{array}{l}-0.25 \\
(0.78)\end{array}$ & $\begin{array}{l}-0.65 \\
(1.37)\end{array}$ & $\begin{array}{l}-0.58 \\
(1.12)\end{array}$ & $\begin{array}{l}1.46^{* *} \\
(0.62)\end{array}$ & $\begin{array}{l}2.81^{*} \\
(1.38)\end{array}$ & $\begin{array}{c}0.95 \\
(0.80)\end{array}$ \\
\hline politics & $\begin{array}{l}-0.21 \\
(0.53)\end{array}$ & $\begin{array}{l}-0.45 \\
(0.77)\end{array}$ & $\begin{array}{l}-0.09 \\
(0.86)\end{array}$ & $\begin{array}{l}-0.39 \\
(0.58)\end{array}$ & $\begin{array}{c}0.12 \\
(1.06)\end{array}$ & $\begin{array}{l}-1.06 \\
(0.91)\end{array}$ \\
\hline work & $\begin{array}{c}0.64 \\
(0.51)\end{array}$ & $\begin{array}{c}0.37 \\
(0.76)\end{array}$ & $\begin{array}{c}1.23 \\
(0.91)\end{array}$ & $\begin{array}{c}0.04 \\
(0.41)\end{array}$ & $\begin{array}{c}0.14 \\
(0.95)\end{array}$ & $\begin{array}{l}-0.19 \\
(0.62)\end{array}$ \\
\hline luck & $\begin{array}{c}0.27 \\
(0.42)\end{array}$ & $\begin{array}{c}0.34 \\
(0.60)\end{array}$ & $\begin{array}{l}-0.59 \\
(0.94)\end{array}$ & $\begin{array}{c}-0.74 * \\
(0.39)\end{array}$ & $\begin{array}{l}-1.57 \\
(0.92)\end{array}$ & $\begin{array}{l}-0.44 \\
(0.48)\end{array}$ \\
\hline government & $\begin{array}{l}-0.34 \\
(0.40)\end{array}$ & $\begin{array}{l}-0.38 \\
(0.63)\end{array}$ & $\begin{array}{l}-0.43 \\
(0.57)\end{array}$ & $\begin{array}{c}0.14 \\
(0.48)\end{array}$ & $\begin{array}{c}1.04 \\
(1.00)\end{array}$ & $\begin{array}{c}0.27 \\
(0.65)\end{array}$ \\
\hline constant & $\begin{array}{c}3.64 \\
(8.14)\end{array}$ & $\begin{array}{c}12.23 \\
(11.26)\end{array}$ & $\begin{array}{c}5.04 \\
(18.68)\end{array}$ & $\begin{array}{c}1.99 \\
(5.55)\end{array}$ & $\begin{array}{c}-1.03 \\
(16.86)\end{array}$ & $\begin{array}{c}3.62 \\
(7.04)\end{array}$ \\
\hline Observations & 89 & 54 & 35 & 87 & 36 & 51 \\
\hline R-squared & 0.20 & 0.31 & 0.46 & 0.19 & 0.51 & 0.14 \\
\hline
\end{tabular}


Figure 1: Accuracy of Beliefs

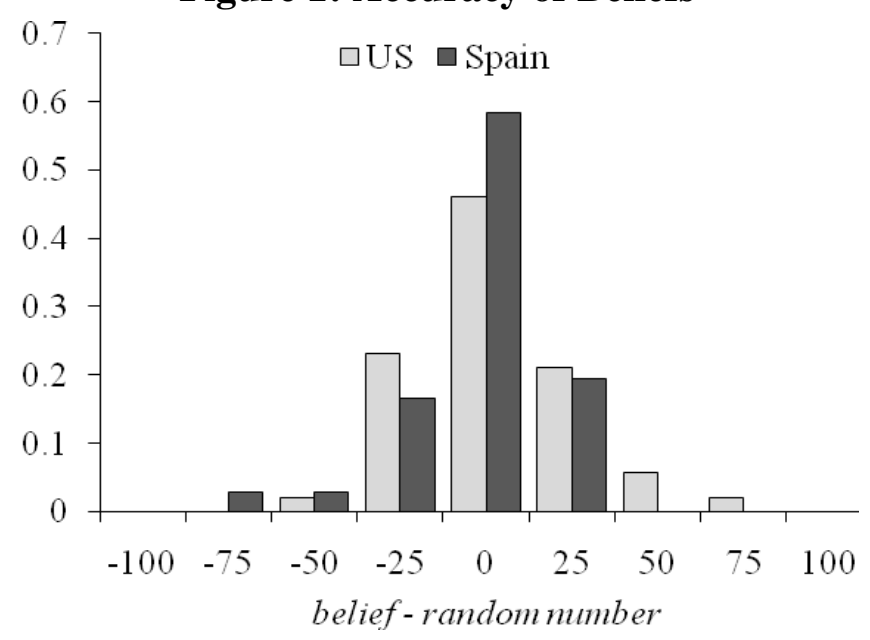

Figure 2: Accuracy of Beliefs Conditional on Low Performance (other-performance $<80$ )

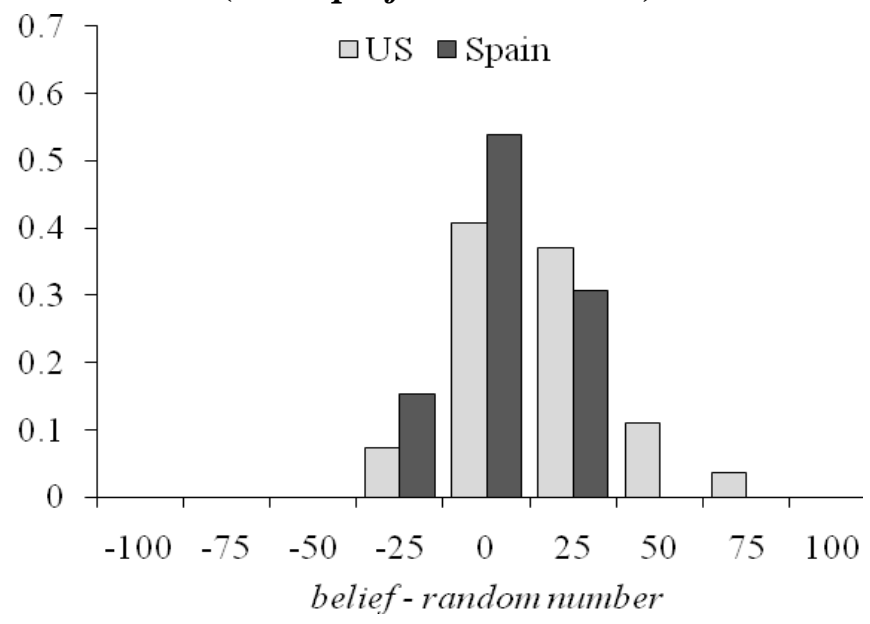

Figure 3: Accuracy of Beliefs Conditional on High Performance (other-performance $>80$ )

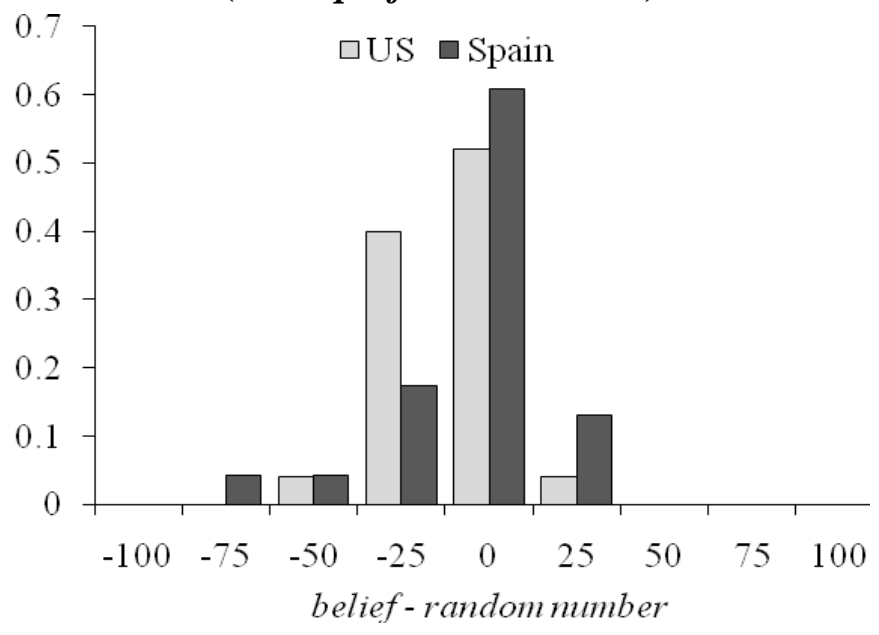




\section{Appendix A - Instructions for the UNINFO Treatment}

Below you can find the instructions for the treatment with no information regarding the determinants of others' income. Instructions for the treatment with information are identical with the exception that the screen in Part II containing information about the other subjects' earnings also includes the number of correct answer and the random number of the paired subject. Instructions for the treatment with information did not contain a Part III of the experiment, where beliefs were elicited.

\section{General Instructions}

Thank you for agreeing to participate in this experiment. Several research agencies have provided funds for this research. Please make sure your cell phones are turned off to avoid interruptions during the proceedings.

This experiment deals with individual decision making. Your participation in this experiment is voluntary. As you know, you will be compensated for your participation; if you read the instructions carefully, you can, depending on yours and other participants' decisions, earn a considerable amount of money in addition to the $\mathbf{\$ 7}$ participation fee. The currency used in the experiment is tokens. Tokens will be converted to US dollars at a rate of $\mathbf{1}$ token to 0.15 US dollars.

The experiment consists of two parts. You will be provided with instructions for Part I of the experiment. After Part I of the experiment is over, you will be provided with instructions for Part II. While you wait to be paid, you will be asked to fill out a questionnaire.

In our experiment, all records will be linked to an anonymous subject ID. At the end of the experiment, you will be paid privately and anonymously. The experimenter will get help from one of her assistants to distribute the payments. The assistant does not know which ID belongs to which participant. The assistant will place the earnings of participants in envelopes with matching ID numbers. After closing the envelopes, the assistant will pass the envelopes to the experimenter. Therefore, nobody, not even the experimenter, will be able to link your decisions to your name during or after the experiment.

Please do not communicate with the other participants during the experiments. Should you have any questions, please raise your hand. At the end of the experiment we will call you, one at a time, to pay you in private.

\section{Pre-instructions}

In the first part of this experiment you will be asked to count the sum of "a" and " $d$ " characters in 50-character sequences. Characters include letters, punctuation marks, numbers, and symbols. Below we provide some examples. Please make sure you understand how we have calculated the sum of "a" and "d" characters in each sequence.

\begin{tabular}{|c|c|c|}
\hline sequence \# & 50-characters sequence & $\begin{array}{c}\text { total number of “a” } \\
\text { and "d" characters }\end{array}$ \\
\hline 1 & aaaaaaaadddaaaaddaaaaaaaaaaaaaaaaaaaaaaaaaa & 50 \\
\hline 2 & 7po6df^gaips78fadfsdfs\&fsdasdftyhgdua*gfrtg(tratra & 12 \\
\hline 3 & p0=jsjd8fjaalkjdflkjds890aaaaaaatrhtr-taatrgtaaaa & 19 \\
\hline 4 & Las9-fakjasklfjalsdjlkjaakljalksaljl=-ddt+gtraaart & 14 \\
\hline
\end{tabular}

Before we start, you will now go through a practice round. Although your final earnings do not depend on the number of correct counts in this practice round, you should try to correctly count all sequences to get practice. We ask you to input into the computer the sum of "a" and "d" characters beside each sequence number, as shown in the following figure. 


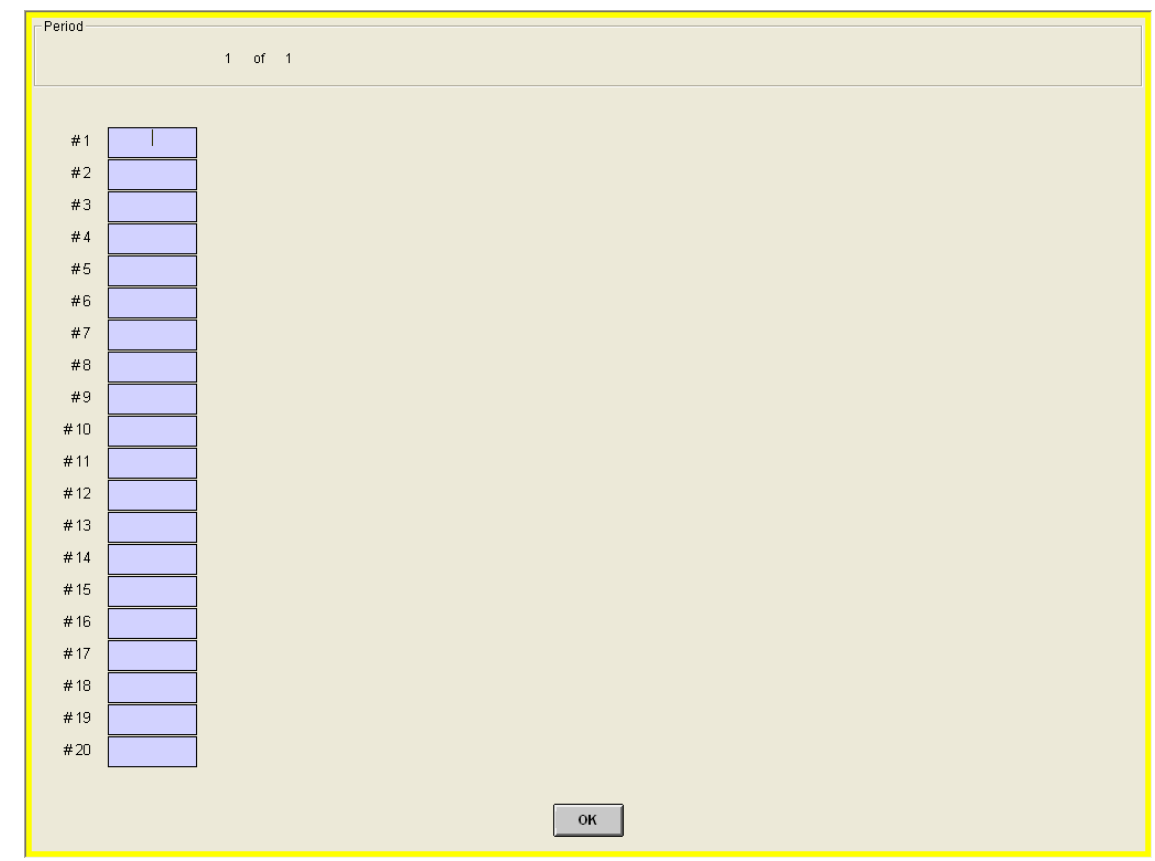

When you finish, the computer will display the correct sum of "a" and "d" characters next to each sequence. If all your answers are correct, both columns should be the same.

Even if you use the following page to make notes, please remember to input each number in the computer as soon as you have calculated it.

\section{Instructions Part I}

In this Part I of the experiment, you will be provided with $\mathbf{3 0 0}$ character sequences. During $\mathbf{3 0}$ minutes you will be asked to count the sum of "a" and " $d$ " characters in each sequence. Your earnings from Part I will depend on your result. Your result will be computed by adding a random number $\mathbf{X}$ to the number of your correct counts:

$($ your result $)=($ your number of correct counts $)+($ your random number $\mathrm{X})$

where your random number $X$ is randomly drawn by the computer and it can be either $\mathbf{- 5 0 ,}-\mathbf{2 5}, \mathbf{0 ,}+\mathbf{2 5}, \mathbf{o r}+\mathbf{5 0}$. Each of these numbers is equally likely to be drawn and may differ for each participant. At the end of this part the computer will make one separate and independent random draw for each participant.

For example, if you correctly count the sum "a" and "d" characters in 82 sequences and the random number X selected by the computer is -25 , your result will be $57=(82-25)$, while if the random number selected by the computer is +50 your result will be $132=(82+50)$. Numbers in this example are just for illustrative purposes and do not intend to indicate how the computer will choose the random number.

After the 30 minutes of the experiment, the computer will randomly draw your random number $\mathrm{X}$ and will calculate your result based on your random number and your number of correct counts. Then the computer will calculate earnings of each participant. Your earnings from Part I are calculated by multiplying your result by 1 token:

(your earnings in Part I $)=($ your result $* 1$ token $)$

Note: if your random number is negative and the number of correct counts is less than your random number then your result will be negative. In such a case, the computer will set your earnings for this part of the experiment to zero. 
You will have $\mathbf{3 0}$ minutes to count the sum of "a" and "d" characters in the 300 sequences we will show you. In any case, you can stop counting characters whenever you want and you do not have to continue until the end. What we ask you is to keep quite during the 30 minutes. In case you decide to take a break, we have left some newspapers for you to read (you are also allowed to take books and lecture notes and read).

The sentences are provided in paper sheets. You are allowed to use a pen. However, you are asked to enter the sum of " $\mathrm{a}$ " and "d" letters before the 30 minutes end to be able to get your earnings.

Please wait until the experimenter gives the start sign.

\section{Instructions Part II}

In this Part II of the experiment you are randomly paired with another participant. To preserve anonymity, neither of you will ever learn with whom you are paired with.

At the beginning of Part II, the computer will display your number of correct counts, your random number (which the computer randomly drew from $\mathbf{- 5 0 , - 2 5 , 0 , + 2 5 , ~ o r ~}+\mathbf{5 0}$ ), and your result in Part I. Remember, the result from Part I is:

$($ your result $)=($ your number of correct counts $)+($ your random number $\mathrm{X})$

Finally, the computer will display your earnings. Remember, earnings from Part I are calculated by multiplying your result by 1 token:

(your earnings in Part I $)=($ your result $) *(1$ token $)$

The computer will also display the result, and the earnings in Part I of your paired participant. The computer WILL NOT show you the number of correct answer or the random number of your paired participant. Remember that your paired participant's random number may be different from your random number since the computer makes two separate random draws: one for you and one for your paired participant.

An example of the display screen is shown below:

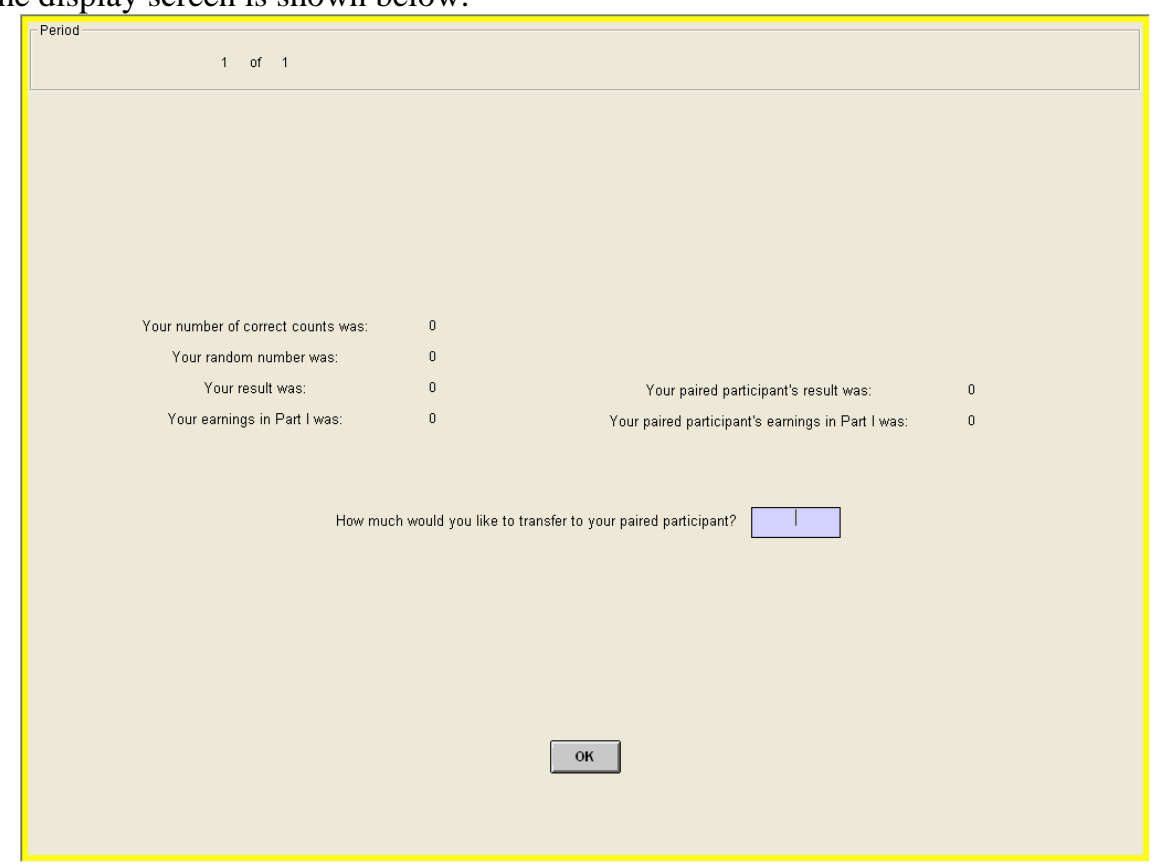


Once the computer displays the screen above, you will make a decision on how much you would like to transfer from your earnings to the other participant's earnings. You will be able to transfer any amount you like. For example, suppose your earnings from Part I is 100 tokens and if the other participant's earnings is 120 tokens. If you enter a transfer of 15 your final earnings will be 85 (=100-15), and the other participant's final earnings will be 135 $(=120+15)$.

Numbers in this example are just for illustrative purposes and do not intend to indicate how you should make your decisions.

Although both you and your paired participant will make the transfer decisions, the computer will randomly implement only one decision made by either you or your paired participant. However, you will not know whose decision will be implemented until the end of the experiment. Since your decision is implemented with $50 \%$ probability, you should pay careful attention to the transfer decision you make.

To summarize, if your decision is randomly picked, then your transfer will decrease your earnings and it will increase your paired participant's earnings. However, you will not get anything from your paired participant's transfer since his/her decision is not implemented. Similarly, if your paired participant's decision is randomly picked, his/her transfer will increase your earnings, and it will decrease his/her earnings. However, you will not transfer anything to your paired participant since your decision is not implemented.

At the end of the experiment you will be paid the total amount of your final income in private and in cash.

In our experiment, all records will be linked to an anonymous subject ID. At the end of the experiment, you will be paid privately and anonymously. The experimenter will get help from one of her assistants to distribute the payments. The assistant does not know which ID belongs to which participant. The assistant will place the earnings of participants in envelopes with matching ID numbers. After closing the envelopes, the assistant will pass the envelopes to the experimenter. Therefore, nobody, not even the experimenter, be able to link your decisions to your name during or after the experiment.

\section{Part III (only for the UNINFO treatment)}

In the screen you just saw, the computer only showed you the result and the earnings in Part I of your paired participant. The computer did not show you the random number of your paired participant.

In this Part II we ask you to make a prediction about the random number of your paired participant. If your guessing is correct you will receive 10 extra experimental points which will add up to your final earnings. If your prediction is not correct you will not earn any additional point.

Remember that your paired participant's random number can be different from yours since the computer chooses them independently among $-50,-25,0,+25$ or +50 . 


\section{Appendix B - Questionnaire}

In order to finish the experiment, and while we calculate your earnings, please fill in the following questionnaire:

\section{Part 1}

1. How hard did you work in the first part of the experiment in a scale from 1 to 10 ?
a. 1
b. 2
c. 3
d. 4
e. 5
f. 6
g. 7
h. 8
i. 9
j. 10

2. How did you decide how much to transfer in the experiment?

\section{Part 2}

1. Gender
a. male
b. female

2. Age

3. Average Monthly Income (including all income sources such as parent's expenses for you)
a. less than $\$ 500$
b. between $\$ 500-1000$
c. more than $\$ 1000$

4. What proportion of your income comes from your own work
a. less than $20 \%$
b. between $20 \%$ and $50 \%$
c. between $50 \%$ and $70 \%$
d. all or almost all

5. What is the importance of family in your life:
a. extremely important
b. very important
c. important
d. somewhat important
e. not very important
f. not important at all

6. What is the importance of religion in your life:
a. extremely important
b. very important
c. important
d. somewhat important
e. not very important
f. not important at all 
7. What is the importance of leisure time in your life:
a. extremely important
b. very important
c. important
d. somewhat important
e. not very important
f. not important at all

8. In political matters, people talk of "the left" and "the right." How would you place your views on this scale, generally speaking?
a. extreme left
b. left
c. left-center
d. center
e. right-center
f. right
g. extreme right

9. Please tell us whether you think the following change is desirable: "Less importance placed on work in our lives"
a. extremely desirable
b. very desirable
c. desirable
d. indifferent
e. not very desirable
f. undesirable
g. extremely undesirable

10. How would you place your views on this: "Hard work doesn't bring success - it's more a matter of luck and connections"
a. I completely agree
b. I agree most of the times
c. I agree
d. I am indifferent
e. I disagree
f. I disagree most of the times
g. I completely disagree

11. How would you place your views on this: "The government should take more responsibility to ensure that everyone is provided for"
a. I completely agree
b. I agree most of the times
c. I agree
d. I am indifferent
e. I disagree
f. I disagree most of the times
g. I completely disagree

12. In what country or region were you born?
a. North America
b. Central/South America
c. Australia/ New Zealand
d. Other Pacific Nation
e. South-East Asia 
f. South Asia

g. Other Asia

h. Western Europe

i. Northern Europe

j. Eastern Europe

k. Africa 


\section{Economic Science Institute Working Papers}

\section{1}

11-10 Deck, C., Porter, D., Smith, V. Double Bubbles in Assets Markets with Multiple Generations.

11-09 Kimbrough, E., Sheremeta, R., and Shields, T. Resolving Conflicts by a Random Device.

11-08 Brañas-Garza, P., García-Muñoz, T., and Hernan, R. Cognitive effort in the Beauty Contest Game.

11-07 Grether, D., Porter, D., and Shum, M. Intimidation or Impatience? Jump Bidding in On-line Ascending Automobile Auctions.

11-06 Rietz, T., Schniter, E., Sheremeta, R., and Shields, T. Trust, Reciprocity and Rules.

11-05 Corgnet, B., Hernan-Gonzalez, R., and Rassenti, S. Real Effort, Real Leisure and Real-time Supervision: Incentives and Peer Pressure in Virtual Organizations.

11-04 Corgnet, B. and Hernán-González R. Don’t Ask Me If You Will Not Listen: The Dilemma of Participative Decision Making.

11-03 Rietz, T., Sheremeta, R., Shields, T., Smith, V. Transparency, Efficiency and the Distribution of Economic Welfare in Pass-Through Investment Trust Games.

11-02 Corgnet, B., Kujal, P. and Porter, D. The Effect of Reliability, Content and Timing of Public Announcements on Asset Trading Behavior.

11-01 Corgnet, B., Kujal, P. and Porter, D. Reaction to Public Information in Markets: How Much Does Ambiguity Matter?

2010

10-22 Mago, S., Sheremeta, R., and Yates, A. Best-of-Three Contests: Experimental Evidence.

10-21 Kimbrough, E. and Sheremeta, R. Make Him an Offer He Can't Refuse: Avoiding Conflicts Through Side Payments.

10-20 Savikhim, A. and Sheremeta, R. Visibility of Contributions and Cost of Inflation: An Experiment on Public Goods.

10-19 Sheremeta, R. and Shields, T. Do Investors Trust or Simply Gamble?

10-18 Deck, C. and Sheremeta, R. Fight or Flight? Defending Against Sequential Attacks in the Game of Siege.

10-17 Deck, C., Lin, S. and Porter, D. Affecting Policy by Manipulating Prediction Markets:

Experimental Evidence. 
10-16 Deck, C. and Kimbrough, E. Can Markets Save Lives? An Experimental Investigation of a Market for Organ Donations.

10-15 Deck, C., Lee, J. and Reyes, J. Personality and the Consistency of Risk Taking Behavior: Experimental Evidence.

10-14 Deck, C. and Nikiforakis, N. Perfect and Imperfect Real-Time Monitoring in a Minimum-Effort Game.

10-13 Deck, C. and Gu, J. Price Increasing Competition? Experimental Evidence.

10-12 Kovenock, D., Roberson, B.,and Sheremeta, R. The Attack and Defense of Weakest-Link Networks.

10-11 Wilson, B., Jaworski, T., Schurter, K. and Smyth, A. An Experimental Economic History of Whalers' Rules of Capture.

10-10 DeScioli, P. and Wilson, B. Mine and Thine: The Territorial Foundations of Human Property.

10-09 Cason, T., Masters, W. and Sheremeta, R. Entry into Winner-Take-All and Proportional-Prize Contests: An Experimental Study.

10-08 Savikhin, A. and Sheremeta, R. Simultaneous Decision-Making in Competitive and Cooperative Environments.

10-07 Chowdhury, S. and Sheremeta, R. A generalized Tullock contest.

10-06 Chowdhury, S. and Sheremeta, R. The Equivalence of Contests.

10-05 Shields, T. Do Analysts Tell the Truth? Do Shareholders Listen? An Experimental Study of Analysts' Forecasts and Shareholder Reaction.

10-04 Lin, S. and Rassenti, S. Are Under- and Over-reaction the Same Matter? A Price Inertia based Account.

10-03 Lin, S. Gradual Information Diffusion and Asset Price Momentum.

10-02 Gjerstad, S. and Smith, V. Household expenditure cycles and economic cycles, 1920 - 2010.

10-01 Dickhaut, J., Lin, S., Porter, D. and Smith, V. Durability, Re-trading and Market Performance. 2009

09-11 Hazlett, T., Porter, D., Smith, V. Radio Spectrum and the Disruptive Clarity OF Ronald Coase.

09-10 Sheremeta, R. Expenditures and Information Disclosure in Two-Stage Political Contests.

09-09 Sheremeta, R. and Zhang, J. Can Groups Solve the Problem of Over-Bidding in Contests? 
09-08 Sheremeta, R. and Zhang, J. Multi-Level Trust Game with "Insider" Communication.

09-07 Price, C. and Sheremeta, R. Endowment Effects in Contests.

09-06 Cason, T., Savikhin, A. and Sheremeta, R. Cooperation Spillovers in Coordination Games.

09-05 Sheremeta, R. Contest Design: An Experimental Investigation.

09-04 Sheremeta, R. Experimental Comparison of Multi-Stage and One-Stage Contests.

09-03 Smith, A., Skarbek, D., and Wilson, B. Anarchy, Groups, and Conflict: An Experiment on the Emergence of Protective Associations.

09-02 Jaworski, T. and Wilson, B. Go West Young Man: Self-selection and Endogenous Property Rights.

09-01 Gjerstad, S. $\underline{\text { Housing Market Price Tier Movements in an Expansion and Collapse. }}$

2008

08-10 Dickhaut, J., Houser, D., Aimone, J., Tila, D. and Johnson, C. High Stakes Behavior with Low Payoffs: Inducing Preferences with Holt-Laury Gambles.

08-09 Stecher, J., Shields, T. and Dickhaut, J. Generating Ambiguity in the Laboratory.

08-08 Stecher, J., Lunawat, R., Pronin, K. and Dickhaut, J. Decision Making and Trade without Probabilities.

08-07 Dickhaut, J., Lungu, O., Smith, V., Xin, B. and Rustichini, A. A Neuronal Mechanism of Choice.

08-06 Anctil, R., Dickhaut, J., Johnson, K., and Kanodia, C. Does Information Transparency Decrease Coordination Failure?

08-05 Tila, D. and Porter, D. Group Prediction in Information Markets With and Without Trading Information and Price Manipulation Incentives.

08-04 Caginalp, G., Hao, L., Porter, D. and Smith, V. Asset Market Reactions to News: An Experimental Study.

08-03 Thomas, C. and Wilson, B. Horizontal Product Differentiation in Auctions and Multilateral Negotiations.

08-02 Oprea, R., Wilson, B. and Zillante, A. War of Attrition: Evidence from a Laboratory Experiment on Market Exit.

08-01 Oprea, R., Porter, D., Hibbert, C., Hanson, R. and Tila, D. Can Manipulators Mislead Prediction Market Observers? 